\title{
Metabolic Clearance of Recombinant Human Growth Hormone in Health and Chronic Renal Failure
}

\author{
Dieter Haffner, Franz Schaefer, Jörg Girard, ${ }^{\star}$ Eberhard Ritz, * and Otto Mehls \\ Departments of Pediatrics and * Internal Medicine, University of Heidelberg, Heidelberg, Germany; and ${ }^{\ddagger}$ University Children's Hospital, \\ Basel, Switzerland
}

\begin{abstract}
Despite the increasing therapeutic use of recombinant human growth hormone ( $r$ GH), its metabolic clearance has not been investigated in detail. To evaluate the kinetics of rhGH as a possible function of GH plasma concentration and glomerular filtration rate (GFR), we investigated the steady state metabolic clearance rate (MCR), disappearance half-life, and apparent volume of distribution of rhGH at low and high physiological as well as supraphysiological plasma GH levels during pharmacological suppression of endogenous GH secretion in human subjects with normal and reduced renal function. GH in plasma and urine was determined by an immunoradiometric assay, and GFR by inulin clearance. In all subjects MCR decreased and plasma half-life increased with increasing plasma $\mathbf{G H}$ concentrations $(P<0.001)$. MCR of rhGH was approximately half in patients with chronic renal failure at each GH level and plasma half-life was increased by $25-50 \%$. Allowing for the linear dependence of MCR on GFR and assuming single-compartment distribution, the estimated renal fraction of total MCR was 25-53 and 4-15\% in controls and patients, respectively. Saturation of extrarenal disposal of GH was suggested by an inverse hyperbolic relationship between extrarenal MCR and plasma GH concentrations in all subjects. Fractional GH excretion was up to $\mathbf{1 , 0 0 0}$-fold higher in patients than in controls. We conclude that MCR of hGH is a function of plasma GH concentrations and GFR. Extrarenal elimination is saturable in the upper physiological range of GH concentrations, whereas renal MCR is independent of plasma GH levels. The kidney handles GH like a microprotein involving glomerular filtration, tubular reabsorption, and urinary excretion. (J. Clin. Invest. 1994. 93:1163-1171.) Key words: growth hormone • pharmacokinetics $\bullet$ renal failure $\bullet$ metabolic clearance $\cdot$ half-life
\end{abstract}

\section{Introduction}

In renal failure plasma concentrations of growth hormone $(\mathrm{GH})^{1}$ both in the fasting state and after stimulation are ele-

Address correspondence to Dr. Otto Mehls, Division of Pediatric Nephrology, University Children's Hospital Heidelberg, Im Neuenheimer Feld 150, 69120 Heidelberg, Germany.

Received for publication 9 August 1993 and in revised form 29 November 1993.

1. Abbreviations used in this paper: $\mathrm{C}_{\text {in }}$, inulin clearance; $\mathrm{CV}$, coefficient of variation; GFR, glomerular filtration rate; $\mathrm{GH}$, growth hormone; GH-BP, growth hormone-binding protein; IRMA, immunoradiometric assay; MCR, metabolic clearance rate; rhGH, recombinant human growth hormone; VD, volume of distribution.

J. Clin. Invest.

(C) The American Society for Clinical Investigation, Inc.

$0021-9738 / 94 / 03 / 1163 / 09 \$ 2.00$

Volume 93, March 1994, 1163-1171 vated (1-3). It has usually been assumed that this reflects abnormal secretion, but so far the role of impaired renal function has not been directly addressed. Clinical interest has recently focused on the metabolic fate of $\mathrm{GH}$, since recombinant human $\mathrm{GH}$ ( $\mathrm{rhGH}$ ) has become available for the treatment of children with renal failure $(4,5)$. However little published information is available on the pharmacokinetic properties of rhGH to date (6).

In previous studies the metabolic clearance rate (MCR) of exogenous $\mathrm{GH}$ in healthy human subjects ranged from 143 to $329 \mathrm{ml} / \mathrm{min}(6-12)$, and plasma half-life ranged from 15 to 51 min $(7,12-15)$. In patients with reduced renal function, reduced $\operatorname{MCR}(12,16)$ and normal (17) or prolonged (12) plasma half-lives of $\mathrm{GH}$ have been reported. The validity of these studies may be questioned on methological grounds since endogenous $\mathrm{GH}$ secretion was not suppressed, a potential concentration dependence of the MCR of GH was not assessed thoroughly, the relative contribution of renal vs. extrarenal elimination was not quantitated, and the radioimmunoassays used were of limited specificity. Furthermore, most studies used extracted pituitary or radiolabeled GH (7-16) of undefined purity. The equivalence of these compounds to endogenous $\mathrm{GH}$ with respect to clearance kinetics has not been determined. Further complexity is added by the recent evidence that $\mathrm{GH}$ is bound to one or more circulating $\mathrm{GH}$ binding proteins (18-20) and that intact GH is also eliminated in human urine (21). In this study we used several new methological accomplishments, such as a highly specific and sensitive immunoradiometric assay (IRMA) and suppression of endogenous GH secretion by a somatostatin analogue to investigate the pharmacokinetics of unlabeled rhGH in healthy human volunteers and in subjects with various degrees of renal failure. To assess a possible concentration dependence of rhGH kinetics, a stepped-dose steady state infusion protocol was applied to evaluate the MCR at three steady state plasma levels, encompassing a range of low physiological to pharmacological GH concentrations.

\section{Methods}

\section{Subjects}

We examined 24 healthy adult volunteers without evidence of renal disease ( 12 male, 12 female, median age, 29 yr [range, 18-62 yr]; glomerular filtration rate [GFR], 127 [range, 83-166] $\mathrm{ml} / \mathrm{min}$ per $1.73 \mathrm{~m}^{2}$ ). None of the subjects was on medication. Nicotine, caffeine, and alcohol were stopped $5 \mathrm{~d}$ before the study. Furthermore, we examined 12 patients, i.e., 6 children (age, $8(4-14)$ years) and 6 adults (age 56 (41-66) years) with chronic renal failure. Six patients ( five of whom children) were in preterminal renal failure and six patients were on dialysis with considerable residual GFR. Underlying renal diseases and individual GFRs are listed in Table I.

None of the patients was on barbiturates or on other agents interfering with hepatic or renal elimination of peptides. In all patients liver disease was excluded by abdominal sonography and by blood chemistry. Malnutrition was excluded by anthropometric measurements. Inu- 
lin clearance was measured using the steady state infusion technique (22). Height was in the lower third percentile for age in all children. GH secretion was evaluated immediately before the study. Normal stimulation with L-arginine ( $>10 \mu \mathrm{g} /$ liter) and a normal night time $\mathrm{GH}$ profile (at least three peaks above $10 \mu \mathrm{g} /$ liter $\mathrm{GH}$ ) were found in each child.

\section{Study design}

The protocol was approved by the ethical committee of the University of Heidelberg. Participants or parents gave informed written consent. The subjects were examined after an overnight fast in a supine position from 7 a.m. to 10 p.m. (see Fig. 1). Two intravenous catheters were placed into the forearms, one for blood sampling and the other for infusions. After blood had been taken for baseline investigations, a continuous infusion of octreotide $\left(2 \mu \mathrm{g} / 1.73 \mathrm{~m}^{2}\right.$ per $\mathrm{h}$; SANDOSTATIN ${ }^{\circledR}$; Sandoz Co., Nürnberg, Germany) was started to suppress endogenous GH secretion. After a baseline period of $60 \mathrm{~min}$, during which endogenous $\mathrm{GH}$ concentrations dropped below the detection limit in each subject, rhGH was infused in three 3-h periods (I-III) separated by wash out periods (Fig. 1). Blood samples were withdrawn at 15 -min intervals during the baseline and the infusion periods; at least nine measurements were performed during the wash out periods. A single batch of rhGH (GENOTROPIN ${ }^{\circledR}$; Kabi Pharmacia, Stockholm, Sweden) was used for infusion in all subjects. It was confirmed by our IRMA used for the determination of rhGH that one bottle of GENOTROPIN ${ }^{\circledR}$ contained $4 \mathrm{mg}$ of rhGH. $4 \mathrm{mg}$ of $\mathrm{rhGH}$ was dissolved in $500 \mathrm{ml}$ isotonic $\mathrm{NaCl}$. One single infusion set and a pump delivering with a precision of $\pm 1 \%$ (PERFUSOR ${ }^{\circledR}$; Braun Co., Melsungen, Germany) were used throughout the study. In the healthy volunteers the infusion rate was increased in a stepwise fashion, i.e., 50, 180, and 310 $\mu \mathrm{g} / \mathrm{m}^{2}$ per $\mathrm{h}$. In a pilot study we noted that renal clearance accounted for $\sim 50 \%$ of total metabolic clearance at plasma GH concentrations of $40-60 \mu \mathrm{g} /$ liter. To achieve similar plasma GH concentrations in healthy controls and in subjects with renal failure, the amount of rhGH administered was therefore adjusted to the estimated GFR, i.e., endogenous creatinine clearance before the study, by multiplying the above infusion rate for healthy volunteers with a coefficient (c):

$c=0.5+0.5 \times \frac{\text { estimated GFR }}{\text { normal GFR }}$,

assuming a normal GFR of $125 \mathrm{ml} / \mathrm{min}$ per $1.73 \mathrm{~m}^{2}$. As shown in Fig. 1 , measurement of actual inulin clearance $\left(\mathrm{C}_{\text {in }}\right)$ at the time of the study was performed during the first and last period of rhGH infusion. A diet of low protein content $(0.3 \mathrm{~g} / \mathrm{kg}$ per d) was administered to both healthy volunteers and subjects with renal failure on the day of the study to prevent diet-induced fluctuations of GFR.

\section{Assays}

Plasma and urine GH was measured using an IRMA as previously described (23). In brief, anti-human GH antiserum was raised in goats. The gamma globulin fraction was covalently coupled to polyacrylamide beads ( Bio-Rad Laboratories, Richmond, CA) and used in a first step for immunoextraction of the biological samples (urine or plasma). After a washing step a ${ }^{125}$ I-labeled monoclonal antibody against human GH (Medix Biochemica, Paris) was added in the second incubation. All measurements were performed in triplicate. The assay was linear within the range used in the study. The detection limit was $0.1 \mu \mathrm{g} /$ liter in plasma and $0.3 \mathrm{ng} /$ liter in urine. The detection limit was defined as the two-step incubation sensitivity of standard 2 pg per tube, multiplied by volume of the unknown used in the first incubation. For the plasma GH determination, the median intraassay coeffcient of variation (CV) calculated from the actual triplicate measurements was $4.8 \%$ in the range of $1-10 \mu \mathrm{g} / \mathrm{liter}, 4.9 \%$ at $10-40 \mu \mathrm{g} / \mathrm{liter}$, and $4.8 \%$ at $40-110 \mu \mathrm{g} /$ liter. The median CV for the urine measurements was $10.5 \%$ at a mean concentration of $23 \mathrm{ng} /$ liter (range, $3-480$ ). All samples of any one study were determined in the same batch. Interassay CVs in plasma and urine were $<11.4 \%$.
Growth hormone binding protein (GH-BP) in plasma was measured by radioligand binding as previously described (24). In a first step, plasma was incubated with ${ }^{125} \mathrm{I}-\mathrm{hGH}$. After filtration through a 0.45-mm minifilter (Millipore Corp., Bedford, MA), the entire incubation mixture was injected into a HPLC Protein Pak 300 sw column (Waters Co., Milford MA). Isocratic elution was carried out using degassed buffers (pumping rate $0.5 \mathrm{ml} / \mathrm{min}$ ). The binding of $\mathrm{GH}$ was expressed as the radioactivity in the individual peak divided by the total radioactivity (peaks I, II, and III). To evaluate nonspecific binding to peak II-BP, $5 \mu \mathrm{g} \mathrm{GH}$ was added to the incubation.

IGF I and IGF II were determined using highly specific RIAs after extraction procedures as previously described $(25,26)$. IGF-BP3 was determined by a specific RIA using an antibody against the pure acidstabile 53-kD binding subunit extracted from plasma Cohn fraction IV (27).

\section{Calculations}

Metabolic clearance rate. The MCR of rhGH, standardized for body surface area, was calculated as $(7,28)$ :

$\operatorname{MCR}\left(\mathrm{ml} / \mathrm{min}\right.$ per $\left.\mathrm{m}^{2}\right)$

$=\frac{\text { infusion rate of } \mathrm{rhGH}\left(\mu \mathrm{g} / \mathrm{min} \text { per } \mathrm{m}^{2}\right)}{\text { steady state plasma } \mathrm{GH} \text { concentration }(\mu \mathrm{g} / \mathrm{ml})}$.

In a pilot study we observed that steady state was achieved after 150 $\mathrm{min}$ as indicated by a slope of zero for linear regression of at least nine measurements. In the final study, steady state concentrations were calculated from the last three measurements of the respective infusion period.

Plasma half-life $\left(t_{1 / 2}\right)$. After the end of each infusion period, plasma half-life was calculated from the decay rate of plasma $\mathrm{GH}$ concentration using a monoexponential regression model. The assumption of a monoexponential decay was confirmed by $R^{2}$ values close to 1 $(0.975 \pm 0.025,0.983 \pm 0.017,0.986 \pm 0.014$ for the three elimination periods).

Volume of distribution (VD). The apparent VD was calculated according to Zilversmit (29) using the following formula:

$\operatorname{VD}\left(\right.$ liters $\left./ \mathrm{m}^{2}\right)=\frac{\operatorname{MCR}\left(\mathrm{ml} / \mathrm{min} \text { per } \mathrm{m}^{2}\right) \times 10^{-3}}{\ln 2 / \mathrm{t}_{1 / 2}(\mathrm{~min})}$.

Fractional urinary excretion. Fractional urinary excretion of GH was calculated as the ratio of $\mathrm{GH}$ urinary clearance and inulin clearance.

\section{Statistics}

Normality of distribution was checked for each variable by the Shapiro Wilk statistic. Since all kinetic parameters were normally distributed, one-way analysis of variance (ANOVA) was performed for all group comparisons. Duncan's test was used for multiple between-subject comparisons; $t$ tests were performed to check for individual within-subject differences. Statistical differences were considered significant for $P$ $\leq 0.05$. Software of the SAS computer package was used for ANOVA, regression, and correlation procedures (30).

\section{Results}

GH-dependent proteins at baseline and after infusion of rhGH. A summary of the GH-dependent protein concentrations before and immediately after the study is given in Table II. Baseline fasting plasma $\mathrm{GH}$ concentrations and $\mathrm{GH}$ binding activity at 7 a.m. did not differ significantly between patients and controls. Of importance for the kinetic analysis below, plasma $\mathrm{GH}$ binding activity did not change significantly during rhGH infusions. Baseline and poststudy plasma IGF-I concentrations were also similar in patients and controls. In concordance with previous reports $(31,32)$, the baseline concentration of IGFBP3 was significantly elevated in uremic subjects. Plasma IGF- 
Table I. Clinical Data of 12 Patients with Chronic Renal Failure

\begin{tabular}{rlcll}
\hline Age & Gender & $\mathrm{C}_{\mathrm{in}}$ & $\begin{array}{c}\text { Treatment } \\
\text { modality }\end{array}$ & \multicolumn{1}{c}{ Underlying renal disease } \\
\hline$y r$ & & ml/min per $1.73 \mathrm{~m}^{2}$ & & \\
41 & $\mathrm{~m}$ & 6 & CAPD & Chronic GN \\
54 & $\mathrm{~m}$ & 7 & CAPD & Chronic GN \\
55 & $\mathrm{~m}$ & 8 & HD & Membranous GN \\
58 & $\mathrm{~m}$ & 8 & HD & IgA-GN \\
14 & $\mathrm{~m}$ & 8 & CAPD & Membranoproliferative GN \\
66 & $\mathrm{~m}$ & 11 & HD & Obstructive uropathy \\
4 & $\mathrm{~m}$ & 17 & $\mathrm{CT}$ & Renal vein thrombosis \\
14 & $\mathrm{~m}$ & 19 & $\mathrm{CT}$ & Focal segmental \\
& & & & glomerulosclerosis \\
8 & $\mathrm{~m}$ & 22 & $\mathrm{CT}$ & Renal dysplasia \\
57 & $\mathrm{f}$ & 29 & $\mathrm{CT}$ & Polycystic kidney disease \\
11 & $\mathrm{~m}$ & 31 & $\mathrm{CT}$ & Nephronophthisis \\
10 & $\mathrm{~m}$ & 42 & $\mathrm{CT}$ & Chronic interstitial nephritis \\
& & & &
\end{tabular}

CAPD, continuous ambulatory peritoneal dialysis; HD, hemodialysis; CT, conservative treatment; GN, glomerulonephritis; $m$, male; $f$, female.

BP3 failed to increase significantly in either group during the 720 min infusion of rhGH.

Analysis of $G H$ kinetics. Table III summarizes the steady state plasma $\mathrm{GH}$ concentrations and the calculated kinetic parameters for each infusion period in the patient and control group, respectively. We found no significant differences in MCR between males and females in the control group (MCR at plasma GH concentrations of $\sim 50 \mu \mathrm{g} /$ liter: males, $112 \pm 5.2$ vs. $113 \pm 4.8 \mathrm{ml} / \mathrm{min}$ per $\mathrm{m}^{2}$ in females; NS). We also failed to observe a sex-related difference in postinfusion elimination half-life and in the apparent volume of distribution of $\mathrm{GH}$ (data not given).
MCR of GH decreased with rising GH steady state concentrations in patients and controls $(P<0.001)$. This point is further illustrated in Fig. $2 a$. MCR decreased with increasing GH steady state concentration in each individual subject of the control and patient groups, respectively. At each given $\mathrm{GH}$ infusion rate, higher steady state levels were observed in pediatric patients than in adult patients and controls. The nonlinear regression equations fitting the relationship between plasma GH and MCR were almost identical in uremic children and adults. A significant difference in MCR between controls and uremic patients was found at each level of $\mathrm{GH}$ infusion ( $P$ $<0.001)$. The lower MCR observed in uremic children than in uremic adults ( Table III) was entirely attributable to the higher average $\mathrm{GH}$ steady state levels achieved.

In the controls a hyperbolic relationship was noted between MCR and GH concentration at every given infusion period. This is the predictable mathematical consequence of the fact that an identical infusion rate per unit body surface was given to all healthy individuals. By necessity MCR was inversely proportional to plasma $\mathrm{GH}$ concentration.

Postinfusion elimination half-life $\left(t_{1 / 2}\right)$ of plasma GH increased significantly $(P<0.001)$ with increasing mean steady state GH concentrations from infusion period I to III both in controls and in uremic patients. A positive relationship was observed between steady state plasma $\mathrm{GH}$ concentration and $t_{1 / 2}$ during the post-steady state elimination periods in both patients $(r=0.67, P<0.0001)$ and controls $(r=0.65, P$ $<0.0001)$. For each infusion period, $t_{1 / 2}$ was significantly $(P$ $<0.001)$ prolonged in uremic patients. There was a negative overall relationship between postinfusion $t_{1 / 2}$ and $C_{\text {in }}$ for each infusion period (infusion period I: $r=-0.56, P<0.001$; II: $r$ $=-0.61, P<0.0001$; III: $r=-0.64, P<0.0001)$. $\mathrm{C}_{\text {in }} \operatorname{did}$ not change significantly between infusion periods I and III (not given ).

As a consequence of the concentration-dependent changes in MCR and $t_{1 / 2}$ the VD decreased significantly $(P<0.01)$ from infusion period I to II, with no further change from infu-
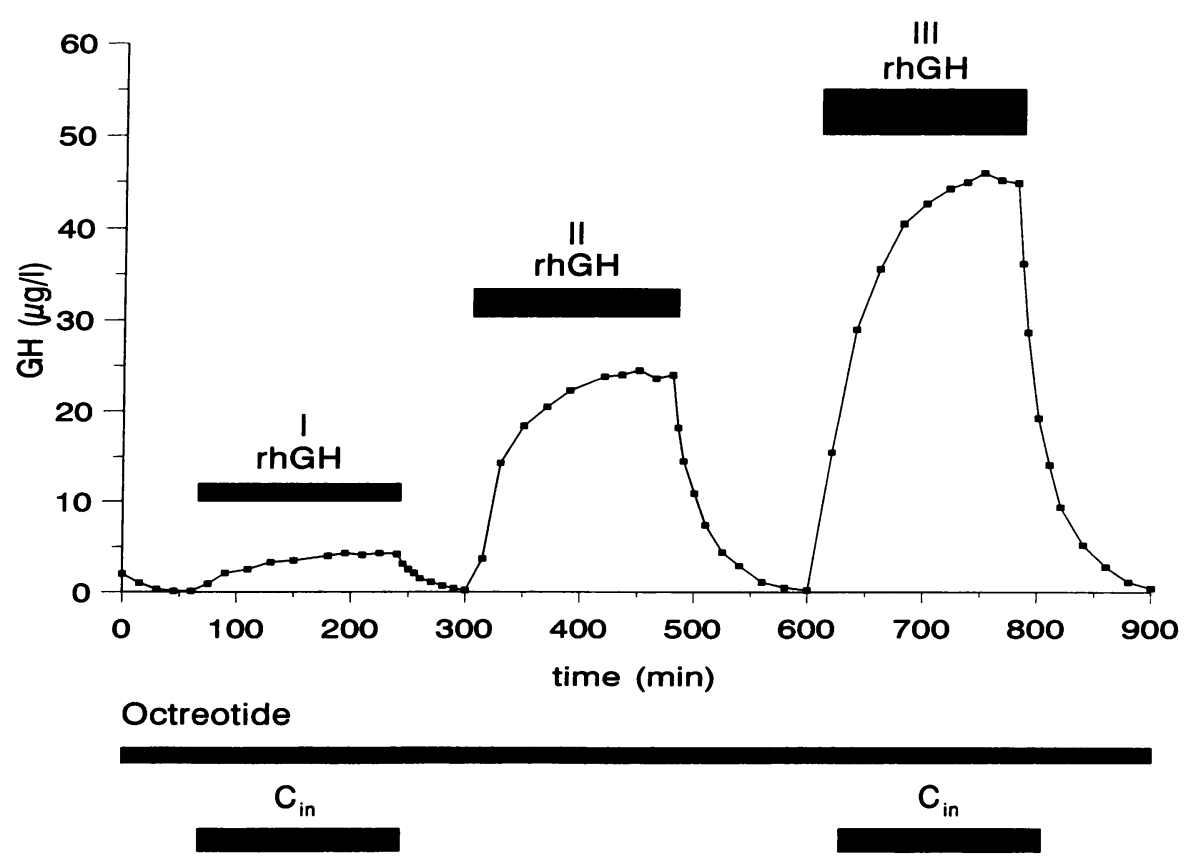

Figure 1. Illustration of study protocol (case no. 10). Endogenous GH secretion was suppressed by octreotide ( $2 \mu \mathrm{g} / 1.73$ $\mathrm{m}^{2}$ per $\mathrm{h}$ ) throughout the experiment. rhGH was administered at stepped-dose infusion rates, i.e., $50 \mu \mathrm{g} / \mathrm{m}^{2}$ per $\mathrm{h}$ from minutes 60 to 240 (infusion period I), 180 $\mu \mathrm{g} / \mathrm{m}^{2}$ per $\mathrm{h}$ from minutes 300 to 480 (infusion period II), and $310 \mu \mathrm{g} / \mathrm{m}^{2}$ per $\mathrm{h}$ from minutes 600 to 780 (infusion period III). Each infusion period was followed by a wash-out period of 60 (I) or 120 (II, III) min. In uremic individuals the amount of rhGH infused was adjusted to GFR as described in the text. Measurement of actual inulin clearance $\left(\mathrm{C}_{\text {in }}\right)$ was performed during the first and last period of rhGH infusion. 
Table II. GH-dependent Proteins at Baseline and after Infusion of rhGH

\begin{tabular}{|c|c|c|c|c|c|}
\hline & GH & GH-BP activity* & IGF I & IGF II & IGF-BP3 \\
\hline & $\mu \mathrm{g} / \mathrm{liter}$ & $\%$ & $\mu g / l i t e r$ & $\mu \mathrm{g} / \mathrm{liter}$ & $\mu g /$ liter \\
\hline \multicolumn{6}{|l|}{ Controls $(n=24)$} \\
\hline Baseline & $1.3 \pm 1.0$ & $44.6 \pm 9.8$ & $200 \pm 80.9$ & $539 \pm 94.5$ & $3,368 \pm 713$ \\
\hline $\begin{array}{l}\text { End of infusion } \\
\text { Period } \mathrm{III}^{\ddagger}\end{array}$ & $45.6 \pm 7.1$ & $42.5 \pm 9.5$ & $236 \pm 79.5^{\S}$ & $542 \pm 95.4$ & $3,382 \pm 697$ \\
\hline \multicolumn{6}{|l|}{ Patients } \\
\hline \multicolumn{6}{|l|}{ Adults $(n=6)$} \\
\hline Baseline & $1.5 \pm 1.4$ & $42.5 \pm 10.5$ & $216 \pm 83.2$ & $638 \pm 183$ & $4,785 \pm 1,425^{\| \prime}$ \\
\hline $\begin{array}{l}\text { End of infusion } \\
\text { Period } \mathrm{III}^{\ddagger}\end{array}$ & $50.1 \pm 7.5$ & $38.5 \pm 10.4$ & $288 \pm 96.5^{11}$ & $676 \pm 179$ & $4,348 \pm 1,286^{\prime \prime}$ \\
\hline \multicolumn{6}{|l|}{ Children $(n=6)$} \\
\hline Baseline & $1.4 \pm 1.3$ & $38.3 \pm 9.5$ & $157 \pm 56.7$ & $528 \pm 102$ & $4,701 \pm 946^{\prime \prime}$ \\
\hline $\begin{array}{l}\text { End of infusion } \\
\text { Period } \mathrm{III}^{\ddagger}\end{array}$ & $85.5 \pm 8.7$ & $35.7 \pm 6.8$ & $190 \pm 51.3^{\pi}$ & $508 \pm 127$ & $4,827 \pm 1,053^{\prime \prime}$ \\
\hline
\end{tabular}

* GH-BP activity refers to peak II of HPLC elution profile. ${ }^{\ddagger}$ Postinfusion GH-BP activity was measured at the end of elimination period III. ${ }^{\S}$ Significant difference, end of infusion period III vs. baseline, $P<0.001$. "Significant difference, patients vs. controls $P<0.05$. 'Significant difference, end of infusion period III vs. baseline, $P<0.05$.

sion period II to III ( Table III ). At comparable GH levels (e.g., infusion period III in adult uremics and controls vs. infusion period II in uremic children ) there was no significant difference between controls and uremic children and adults respectively.

To further elucidate the relative contributions of renal and extrarenal metabolic clearance to diminished overall metabolic clearance in uremic patients, estimates of the two components were calculated. In healthy subjects a linear relationship was noted between total MCR and $\mathrm{C}_{\text {in }}$ during each infusion period (I: $r=0.65, P<0.05$; II: $r=0.67, P<0.01$; III: $r=0.73, P$
$<0.001$; see also Fig. 3 ). When the regression line calculated between $C_{\text {in }}$ and MCR in normal subjects was extrapolated to the $C_{\text {in }}$ range of the patients with renal failure, the observed MCR values closely fitted those predicted by the regression line established in the normal GFR range. The mean coefficient of variation of the estimate in infusion periods I-III was 20,16, and $15 \%$, respectively.

The regression slope between $\mathrm{MCR}$ and $\mathrm{C}_{\text {in }}$ in infusion period $3(Y=89+0.80 \times X)$ is consistent with a glomerular sieving coefficient of 0.8 . The calculated sieving coefficients in

Table III. Pharmacokinetics of rhGH in 24 Healthy Subjects and 12 Patients with Chronic Renal Failure

\begin{tabular}{|c|c|c|c|c|}
\hline & & \multirow[b]{2}{*}{$\begin{array}{l}\text { Controls } \\
(n=24)\end{array}$} & \multicolumn{2}{|c|}{ Patients } \\
\hline & & & $\begin{array}{l}\text { Adults } \\
(n=6)\end{array}$ & $\begin{array}{c}\text { Children } \\
(n=6)\end{array}$ \\
\hline \multirow[t]{5}{*}{ Infusion period I (minutes 60-240) } & GH concentration steady state $(\mu \mathrm{g} /$ liter $)$ & $3.7 \pm 1.3^{*}$ & $3.2 \pm 0.8^{*}$ & $7.2 \pm 1.2^{\ddagger}$ \\
\hline & $\operatorname{MCR}\left(\mathrm{ml} / \mathrm{min}\right.$ per $\left.\mathrm{m}^{2}\right)$ & $206 \pm 60.4^{*}$ & $175 \pm 29.7^{\ddagger}$ & $109 \pm 21.5^{\S}$ \\
\hline & $t_{1 / 2}(\min )$ & $13.0 \pm 3.8^{*}$ & $18.7 \pm 4.7^{\ddagger}$ & $24.7 \pm 3.9^{\S}$ \\
\hline & VD (liters $/ \mathrm{m}^{2}$ ) & $3.76 \pm 1.21^{\prime \prime}$ & $4.38 \pm 1.31$ & $3.53 \pm 0.74$ \\
\hline & (\% body weight) & $10.9 \pm 4.33^{\prime \prime}$ & $11.6 \pm 3.96$ & $12.9 \pm 3.21$ \\
\hline \multirow[t]{5}{*}{ Infusion period II (minutes $300-480$ ) } & GH concentration steady state $(\mu \mathrm{g} /$ liter $)$ & $25.2 \pm 4.2^{*}$ & $26.3 \pm 5.4^{*}$ & $43.8 \pm 6.3^{\ddagger}$ \\
\hline & $\operatorname{MCR}\left(\mathrm{ml} / \mathrm{min}\right.$ per $\left.\mathrm{m}^{2}\right)$ & $124 \pm 21.8^{*}$ & $94 \pm 17.6^{\ddagger}$ & $58 \pm 5.5^{\S}$ \\
\hline & $t_{1 / 2}(\min )$ & $18.0 \pm 5.3^{*}$ & $24.8 \pm 2.8^{\ddagger}$ & $29.1 \pm 2.7^{\S}$ \\
\hline & VD (liters $\left./ \mathrm{m}^{2}\right)$ & $3.09 \pm 0.86^{*}$ & $3.06 \pm 0.24^{*}$ & $2.29 \pm 0.11^{\ddagger}$ \\
\hline & (\% body weight) & $8.21 \pm 3.07^{\prime \prime}$ & $7.86 \pm 1.74$ & $7.13 \pm 1.43$ \\
\hline \multirow[t]{5}{*}{ Infusion period III (minutes $600-780$ ) } & GH concentration steady state $(\mu \mathrm{g} /$ liter $)$ & $45.6 \pm 7.1^{*}$ & $50.1 \pm 7.5^{*}$ & $85.5 \pm 8.7^{\ddagger}$ \\
\hline & $\operatorname{MCR}\left(\mathrm{ml} / \mathrm{min}\right.$ per $\left.\mathrm{m}^{2}\right)$ & $113 \pm 17.1^{*}$ & $68 \pm 5.8^{\ddagger}$ & $47 \pm 1.5^{\S}$ \\
\hline & $t_{1 / 2}(\min )$ & $20.5 \pm 4.5^{*}$ & $28.1 \pm 3.0^{\ddagger}$ & $31.8 \pm 2.5^{\ddagger}$ \\
\hline & VD (liters/m²) & $3.13 \pm 0.98^{\prime \prime}$ & $2.65 \pm 0.21$ & $2.13 \pm 0.19$ \\
\hline & (\% body weight) & $8.33 \pm 3.51^{11}$ & $6.80 \pm 0.94$ & $6.51 \pm 1.56$ \\
\hline
\end{tabular}

MCR, metabolic clearance rate evaluated by steady state infusion; $t_{1 / 2}$, plasma disappearance half-life after withdrawal of rhGH infusion; VD, apparent volume of distribution. Different footnote symbols within a row denote significant differences between the groups $(P<0.05)$. "NS. 

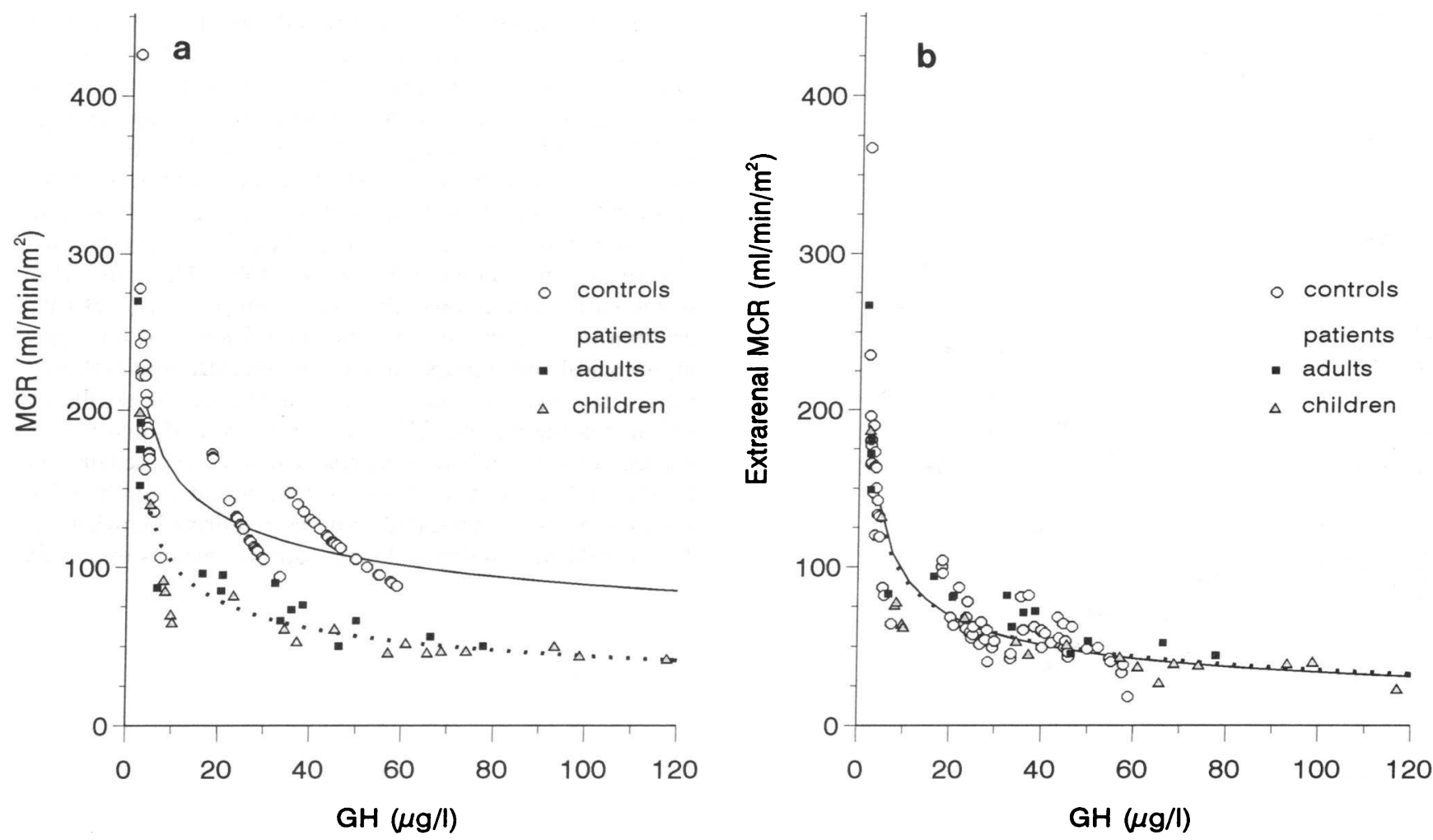

Figure 2. Total MCR and calculated extrarenal MCR as a function of steady state plasma GH concentrations in controls and uremic subjects. (a) Total MCR was expressed as a power function of steady state GH concentration $\left(Y=A \times X^{\mathbf{B}}\right)$ in controls (solid line) and in uremic patients (dotted line). Controls: $Y=280 \times X^{-0.253} ; r=-0.88 ; P<0.0001$. Uremic patients: $Y=243 \times X^{-0.371} ; r=-0.92 ; P<0.0001$. (b) Extrarenal MCR was estimated as the difference between total MCR and renal MCR. It was identical in controls and uremic patients (see text). Extrarenal $\operatorname{MCR}(Y)$ was a power function function of steady state GH concentration $(X): Y=309 \times X^{-0.478} ; r=-0.86 ; P<0.0001$.

infusion periods I and II were 0.65 and 0.8 , respectively. Using these sieving coefficients, renal clearances $\left(\left[\mathrm{C}_{\mathrm{in}} / 1.73\right] \times\right.$ sieving coefficient) were calculated and subtracted from total MCR.

Fig. $2 b$ gives the resulting differences between total MCR and calculated renal clearance, i.e., extrarenal MCR, in controls and patients, respectively. Whereas total MCR was lower in uremic patients at any given level of plasma GH (Fig. $2 a$ ), extrarenal MCR was in the same range as in controls (Fig. $2 b$ ). A curvilinear relationship was noted between extrarenal MCR and plasma $\mathrm{GH}$. Using a power function $\left(Y=A \times X^{B}\right)$, a highly significant relationship was found in controls and in patients, respectively. Such a relationship is compatible with the assumption of a saturation mechanism for extrarenal disposal of $\mathrm{GH}$ with half-maximal saturation occurring at a plasma $\mathrm{GH}$ concentration of $12 \mu \mathrm{g} /$ liter.

The estimated renal fraction of total MCR increased with increasing plasma GH steady state concentration from infusion period I to III $(P<0.01)$. For the three infusion periods, it amounted to 25 (I), 46 (II), and 53\% (III) in the control group, and 4 (I), 12 (II), and $15 \%$ (III) in the patient group.

Fig. 4 shows the proportion of infused GH excreted in the urine per GFR in controls and in uremic patients, respectively. During each of the three stepped-dose infusion periods fractional excretion was significantly $(P<0.001)$ greater in uremic patients than in controls. The proportion of filtered GH excreted in the urine was $<10^{-4}$ in controls and ranged from $10^{-4}$ to $10^{-1}$ in uremic patients.

\section{Discussion}

This study provides new information on the metabolism of recombinant human $\mathrm{GH}$ in humans. In contrast to previous investigations on this topic, endogenous GH secretion was suppressed and a highly sensitive and specific IRMA was used to measure GH. This allowed us to measure MCR and elimination half-life over a wide range of $\mathrm{GH}$ concentrations, from physiological baseline to pharmacological levels. We were able to demonstrate that $\mathrm{GH}$ clearance is inversely related to total GH plasma concentrations, a finding consistent with dose-dependent saturation of $\mathrm{GH}$-binding protein, saturation of extrarenal elimination mechanisms, or a combination of the two. Moreover, a linear relationship between MCR and GFR in subjects with normal renal function and a reduction of MCR by $50 \%$ in patients with chronic renal failure were observed, suggesting that the kidney is an important route of elimination. In contrast, estimated extrarenal metabolic clearance was not significantly altered in uremic patients. The apparent volume of GH distribution was similar in subjects with normal and reduced renal function. Commensurate with the changes in MCR, postinfusion elimination half-life of rhGH was positively correlated with the steady state plasma GH level, and inversely correlated with GFR.

The observed dose and GFR dependence of GH elimination resolves previous contradictory findings with respect to possible sex- or age-related differences of $\operatorname{GH} \operatorname{MCR}(6,9,10)$. 


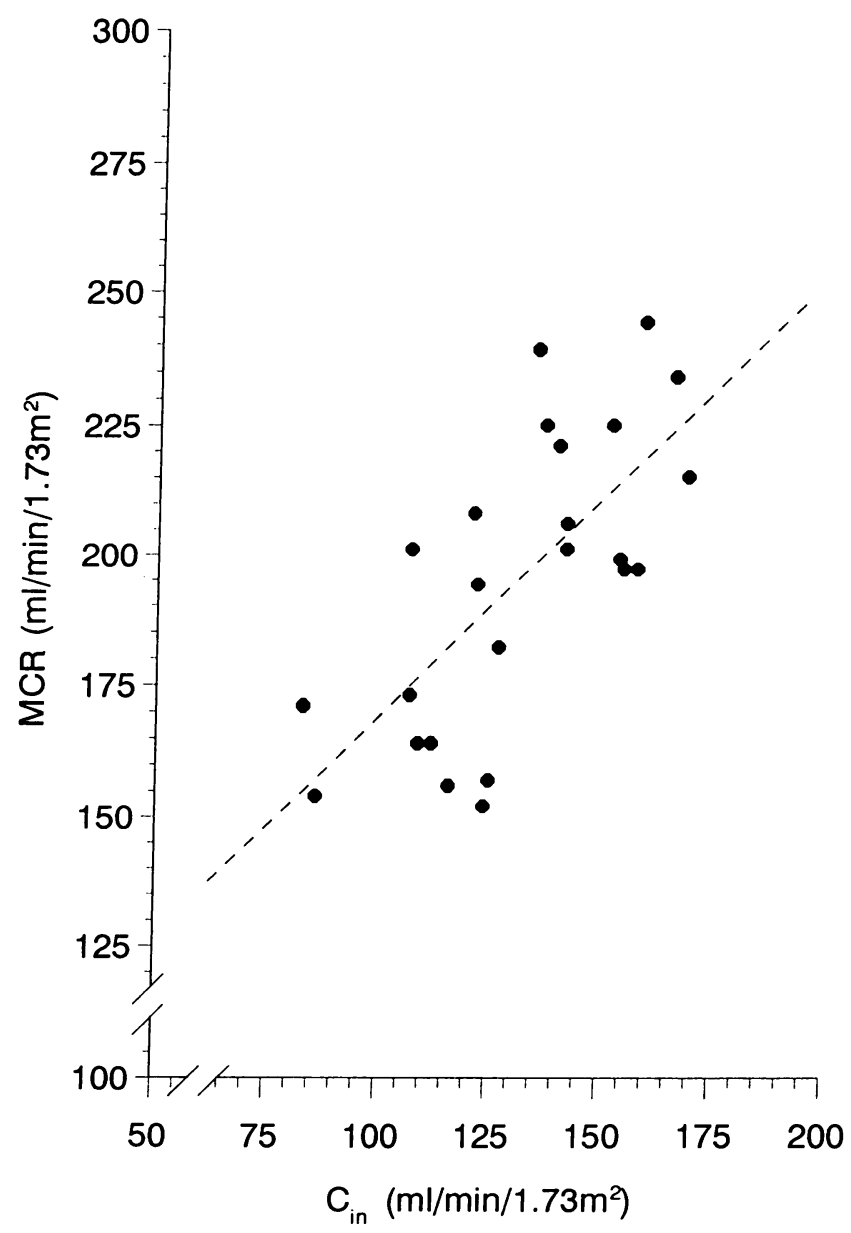

Figure 3. Relationship between inulin clearance and total MCR of $\mathrm{GH}$ in 24 healthy individuals. A significant linear correlation was found: $Y=89+0.8 \times X ; r=0.73 ; P<0.001 . \mathrm{C}_{\text {in }}$ and MCR were calculated from measurements at the end of infusion period III.

When correcting for plasma GH levels, GH kinetics did not differ between male and female subjects nor between uremic adults and uremic children. Urinary GH excretion was increased markedly in patients with chronic renal failure. Under the assumption that the renal handling of $\mathrm{GH}$ resembles that of other microproteins of similar size, including glomerular filtration and tubular reuptake and degradation, this observation suggests saturation of tubular uptake in subjects with reduced functional renal mass.

If the glomerular sieving coefficient of a substance is known, glomerular elimination can be quantified from the GFR, and extrarenal MCR may be estimated by substraction of renal from total metabolic clearance. In perfusion studies of isolated rat kidneys, Johnson and Maack (33) found a glomerular sieving coefficient of $0.58-0.72$ for rat GH. In this study, we observed a linear relationship between MCR and glomerular filtration of $\mathrm{GH}$. If one assumes that $\mathrm{GH}$ is cleared intrarenally exclusively by way of glomerular filtration and that filtered $\mathrm{GH}$ does not reenter the circulation, then the slope of the regression line between GFR and MCR equals the glomerular sieving coefficient. These assumptions appear to be justified since, at least in experimental animals, peritubular uptake and tubular secretion of $\mathrm{GH}$ is small and only degradation products of GH may return to the circulation $(33,34)$. The assumed glomerular sieving coefficient for $\mathrm{GH}$ was 0.65 in the low physiological and 0.8 in the high physiological and supraphysiological GH concentration range. Free filtration of GH ( sieving coefficient $=1.0$ ) may be inhibited by partial restriction at the filtration barrier and/or binding of GH to its circulating binding protein. Baumann et al. (20) found a sixfold higher elimination constant for unbound than for complexed human $\mathrm{GH}$ in the rat. Partial saturation of the GH-binding protein (GH-BP), resulting in an increase in the free GH fraction at the upper physiological and supraphysiological concentration level, may explain the observed rise of the assumed sieving coefficient with increasing plasma GH concentrations. It should be emphasized that the GH kinetics presented here are based on total plasma $\mathrm{GH}$, comprising both protein-bound and -free $\mathrm{GH}$ fractions. More sophisticated analyses, requiring knowledge of the GH-GH-BP binding and dissociation constants in uremia,

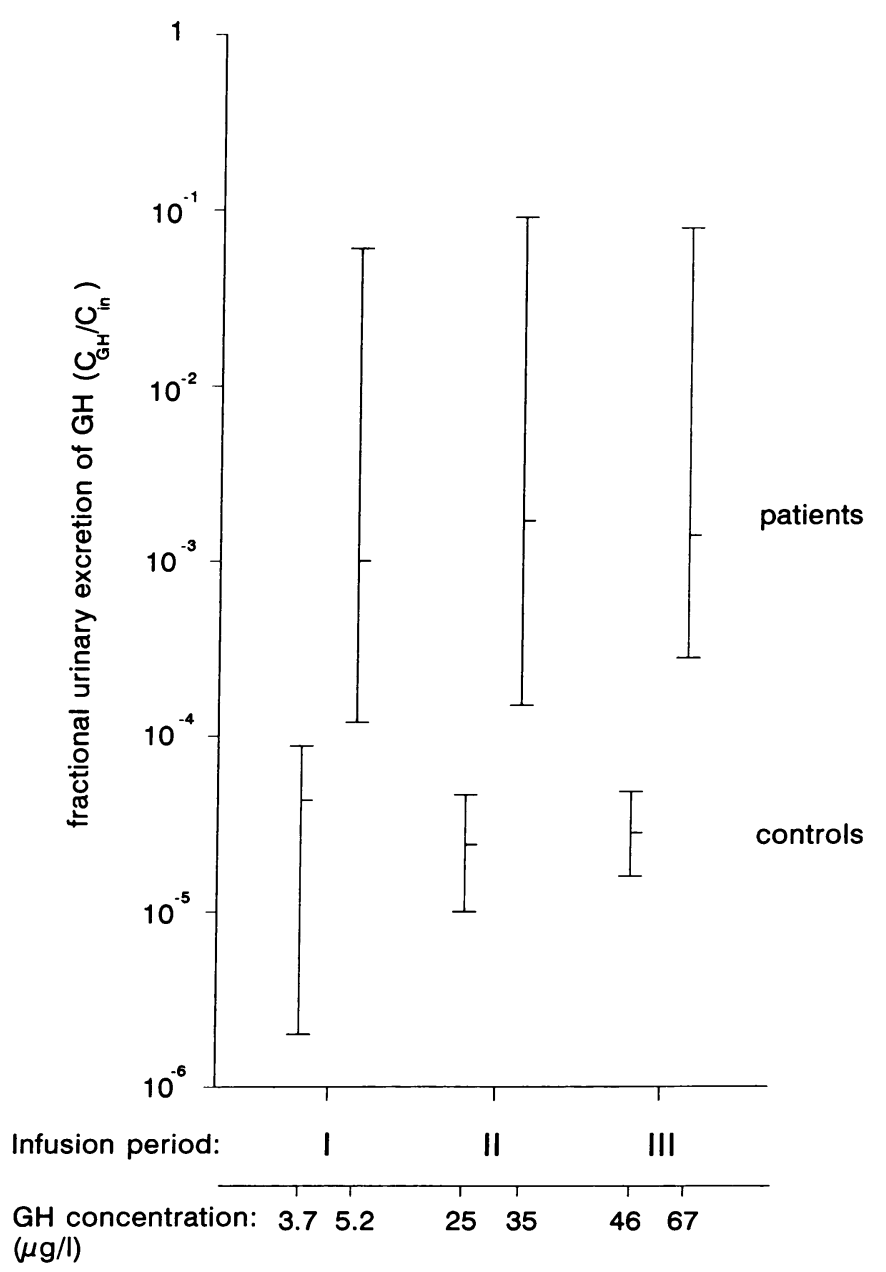

Figure 4. Fractional urinary excretion of GH during the three consecutive infusion periods. Median and range of the proportion of the amount of infused GH excreted in the urine is shown. To compare measurements in controls and uremic patients, values were factored for GFR. The additional abscissa gives the median steady state GH concentrations at the end of the infusion periods. All differences between the two groups were statistically significant $(P<0.001)$. 
would be necessary to differentiate the kinetics of free and complexed GH (35).

While the renal elimination rate constant apparently increased in the high physiological and supraphysiological range of $\mathrm{GH}$ concentrations, a dose-dependent decrease in estimated extrarenal MCR was observed in both normal and uremic subjects. Experimental studies suggest that the main site of extrarenal disposal of GH is the liver (33). Hepatic GH uptake occurs by receptor-mediated endocytosis followed by lysosomal degradation $(36,37)$. Saturation of receptor-mediated binding would be a suitable explanation for the gradual decrease in extrarenal MCR with increasing plasma GH concentrations. According to the study design the highest dose of $\mathrm{GH}$ was always given last in the $15 \mathrm{~h}$ of the study period. We cannot totally exclude the possibility that decreased extrarenal MCR, as seen during the second and third infusion period, was due to a sequence and/or a circadian effect. We feel however, that these explanations are less likely since plasma GH levels decreased to $\leq 0.1 \mu \mathrm{g} /$ liter in each elimination period. Furthermore, supraphysiological plasma GH concentrations were not reached before the third infusion period. We therefore favor the interpretation that decreased extrarenal MCR is a function of, and caused by, increased GH concentrations.

In agreement with previous studies using extracted native (12) or radiolabeled (16) pituitary GH, the total MCR of rhGH was decreased by $50 \%$ in the uremic subjects. When the regression line calculated between GFR and MCR in normal subjects was extrapolated to the GFR range of the patients with renal failure, the observed MCR values closely fitted those expected from a strictly linear relationship between GFR and MCR. In contrast, the estimated extrarenal MCR of rhGH did not differ between subjects with normal and reduced renal function. This is of interest in view of the previously reported reduction in hepatic $\mathrm{GH}$ binding sites on liver tissue of uremic rats (38), and the reported decrease in extrarenal clearance of other peptide hormones in uremia, e.g., parathyroid hormone (39).

The apparent VD of GH exceeded the average plasma volume (i.e., $\sim 5 \%$ of body weight [ 40$]$ ), but was smaller than the extracellular volume (i.e., $\sim 20 \%$ of body weight [40]). This may be explained by binding of GH to GH-BP. The reported progressive saturation of $\mathrm{GH}$ binding above a plasma concentration of $20 \mu \mathrm{g} /$ liter (41) may contribute to the apparent decrease of the volume of distribution at increasing steady state plasma GH concentrations. In addition VD of GH may be reduced by decreasing extrarenal MCR due to progressive saturation of receptor-mediated uptake of $\mathrm{GH}$. In contrast to an earlier report using extracted pituitary $\mathrm{GH}$ (12), we observed no difference in the VD of rhGH between normal controls and patients with renal failure.

The study setting allowed us to accurately determine the removal rate of rhGH from plasma after the end of each steady state infusion. Since the VD could be considered to be completely saturated at the time of $\mathrm{rhGH}$ withdrawal, a monocompartment elimination model wàs applied. Although redistribution of GH from subcompartments such as the GH-BP was not allowed for, the excellent explained variance obtained by the monoexponential model suggests that valid estimates of total GH plasma half-life were achieved. The calculated mean plasma half-life of $18 \mathrm{~min}$ observed after infusion period II is very close to the figure calculated by a biexponential model from endogenous $\mathrm{GH}$ pulses induced by sequential administration of GHRH and somatostatin (42). As a direct confirmation of the MCR results, we observed a positive relationship between GH half-life and the plasma $\mathrm{GH}$ levels present at the time when the infusion was stopped. This observation, which was noted in both control and uremic subjects, has potential implications for the mathematical algorithms used for estimation of $\mathrm{GH}$ secretion and elimination rates in spontaneous $\mathrm{GH}$ concentration time series. If the rate of $\mathrm{GH}$ removal after a secretory burst is not stable, but dependent on the instantaneous plasma $\mathrm{GH}$ concentration, this factor should be allowed for in respective computerized models.

Commensurate with the change of MCR, plasma disappearance half-life of rhGH was consistently prolonged by $\sim 40 \%$ during each postinfusion period in uremic compared with normal adults. These findings confirm some (12) though not all (17) previous GH half-life estimates in uremic subjects. They are also in general agreement with the results obtained by deconvolution analysis of endogenous $\mathrm{GH}$ secretory bursts in patients with chronic renal failure $(43,44)$, although, probably due to dynamic changes in VD saturation during spontaneous $\mathrm{GH}$ release and to sampling frequency-related limited precision of burst analysis, a wider variability has been observed in these investigations.

Differences in GH kinetics between children and adults have been reported (6). We observed an inverse overall relationship between MCR and age in healthy adults $(r=-0.5, P$ $<0.05$ ). However, this association may be spurious, since both variables were significantly correlated with GFR; the latter decreased with age $(r=-0.47, P<0.05)$. If GFR is taken into account, in adults age per se is no longer a significant determinant of MCR. Although it is tempting to extrapolate this conclusion to children and adolescents, it has to be pointed out that children with normal renal function were not evaluated. However, we also failed to see a significant difference of MCR between uremic children and adults at comparable plasma $\mathrm{GH}$ levels.

In normal subjects, only a minute proportion of filtered $\mathrm{GH}(\sim 0.01 \%)$ is excreted in the final urine $(45)$. In agreement with previous observations in uremic children and adults $(46,47)$, we noted increased urinary $\mathrm{GH}$ excretion in subjects with renal failure. This may be explained by partial saturation of tubular reabsorption/degradation (33), as reported for other microproteins such as $\beta_{2}$-microglobulin (48) and others (49). Urinary GH excretion is increasingly used as an index of $\mathrm{GH}$ secretion $(50,51)$. In patients with chronic renal failure, the use of urinary $\mathrm{GH}$ excretion for quantitating circulating GH is restricted by its GFR dependence. Although the amount of $\mathrm{GH}$ excreted in the urine increases in renal failure by two orders of magnitude, the absolute contribution of urinary excretion to renal MCR remains small (i.e., $\sim 0.3 \%$ ). Moreover, the modification of postglomerular handling should not affect overall renal clearance of the hormone, provided that, as discussed above, enhanced tubular secretion is not a major mechanism of GH elimination in uremia (33).

The cumulative dose of $\mathrm{GH}$ infused during the study in the controls exceeded by approximately fivefold the expected endogenous $\mathrm{GH}$ production rate based on published estimates (52). GH stimulates the production of IGF I, which in turn stimulates GFR (53). In this study, only a modest increase in IGF I and no change in GFR was observed, which may be due 
to the short duration ( $720 \mathrm{~min}$ ) of rhGH infusion. $\mathrm{GH}$ binding activity did not change significantly. Thus it appears unlikely that the GH infusions during the study period had a significant effect on GFR and, in consequence, GH kinetics.

In the treatment of stunted children with chronic renal failure, a dose of $1.33 \mathrm{mg} \mathrm{rhGH} / \mathrm{m}^{2}$ per $\mathrm{d}$ is usually administered subcutaneously once daily. This leads to peak plasma GH concentrations in the range of $80 \mu \mathrm{g} / \mathrm{liter} 4 \mathrm{~h}$ after injection (54). Besides the reduced renal MCR in these patients, our findings indicate that extrarenal MCR is also saturated at such peak plasma GH concentrations. Although no accumulation has been observed with $1.33 \mathrm{mg} \mathrm{rhGH} / \mathrm{m}^{2}$ per $\mathrm{d}(54)$, treatment with even higher doses, as presently discussed for nonresponders and pubertal patients, may be critical. Moreover, the observed GFR dependence of rhGH MCR should be taken into account when tailoring individual GH dosages in subjects with chronic renal failure. At a given dose of rhGH standardized for body surface area, the time-averaged concentrations of GH that the target tissues are exposed to will be directly inversely related to GFR. This may in part explain the large intraindividual differences in growth response to rhGH in children with chronic renal failure $(55,56)$. Finally, if receptormediated hepatic uptake of the hormone is the major mechanism of extrarenal rhGH clearance, it may be altered during long-term rhGH administration by changes in receptor expression. Therefore, longitudinal studies of rhGH kinetics should be performed in treated patients.

\section{Acknowledgments}

We thank Dr. M. C. Postel-Vinay (Paris) for determination of growth hormone binding activity and Dr. W. Blum (Department of Pediatrics, Tübingen) for determination of IGF I, IGF II, and IGF-BP3. GENOTROPIN $^{\circledR}$ (rhGH) was a gift of Kabi (Pharmacia, Stockholm, Sweden). Dr. Haffner is recipient of a postgraduate scholarship granted by the Deutsche Forschungsgemeinschaft.

\section{References}

1. Samaan, N. A., and R. M. Freeman. 1970. Growth hormone levels in severe renal failure. Metabolism. 19:102-113.

2. Ramirez, G., W. M. O’Neill, H. A. Bloomer, and W. Jubiz. 1978. Abnormalities in the regulation of growth hormone in chronic renal failure. Arch. Intern. Med. 138:267-271.

3. Schaefer, F., G. Hamill, R. Stanhope, M. A. Preece, K. Schărer, and the Cooperative Study Group on Pubertal Development in Chronic Renal Failure. 1991. Pulsatile growth hormone secretion in peripubertal patients with chronic renal failure. J. Pediatr. 119:568-577.

4. Koch, V. H., B. M. Lippe, P. A. Nelson, M. I. Boechat, B. M. Sherman, and R. N. Fine. 1989. Accelerated growth after recombinant human growth hormone treatment of children with chronic renal failure. J. Pediatr. 115:365-371.

5. Tönshoff, B., O. Mehls, U. Heinrich, W. F. Blum, and M. B. Ranke. 1990. Growth-stimulating effects of recombinant human growth hormone in children with end-stage renal disease. J. Pediatr. 116:561-566.

6. Rosenbaum, M., and J. M. Gertner. 1989. Metabolic clearance of synthetic human growth hormone in children, adult women, and adult men. J. Clin. Endocrinol. \& Metab. 69:821-824.

7. Parker, M. L., R. D. Utiger, and W. H. Daughady. 1962. Studies on human growth hormone. II. The physiological disposition and metabolic rate of human growth hormone in man. J. Clin. Invest. 41:262-270.

8. Cameron, D. P., H. G. Burger, K. J. Catt, and A. Doig. 1969. Metabolic clearance rate of radiodinated human growth hormone in man. J. Clin. Invest. 48:1600-1608.

9. Taylor, A. L., J. L. Finster, and D. H. Mintz. 1969. Metabolic clearance and production rates of human growth hormone. J. Clin. Invest. 48:2349-2358.

10. MacGillivray, M. H., L. A. Frohman, and J. Doe. 1970. Metabolic clearance and production rates of human growth hormone in subjects with normal and abnormal growth. J. Clin. Endocrinol. \& Metab. 30:632-638.
11. Kowarski, A., R. G. Thompson, C. J. Migeon, and R. M. Blizzard. 1971. Determination of integrated plasma concentrations and true secretion rates of human growth hormone. J. Clin. Endorinol. \& Metab. 32:356-360.

12. Owens, D., M. C. Srivastave, C. V. Tompkins, J. D. N. Nabarro, and P. H. Sönksen. 1973. Studies on the metabolic clearance rate, apparent distribution space and plasma half-disappearance time of unlabelled human growth hormone in normal subjects and in patients with liver disease, renal disease, thyroid disease and diabetes mellitus. Eur. J. Clin. Invest. 3:284-294.

13. Boucher, B. J. 1966. Disappearance of iodine-131-labelled human growth hormone from the plasma of diabetic, non-diabetic and acromegalic subjects. Nature (Lond.). 210:1288-1295.

14. Refetoff, S., and P. H. Sonksen. 1970. Disappearance rate of endogenous and exogenous human growth hormone in man. J. Clin. Endocrinol. \& Metab. 30:386-391.

15. Hendricks, C. M., R. C. Eastman, S. Takeda, K. Asakawa, and P. Gordon. 1985. Plasma clearance of intravenously administered pituitary human growth hormone: gel filtration studies of heterogenous components. J. Clin. Endocrinol. \& Metab. 60:864-867.

16. Cameron, D. P., H. G. Burger, K. V. Catt, E. Gordon, and J. Watts. 1972. Metabolic clearance of human growth hormone in patients with hepatic and renal failure, and in the isolated perfused pig liver. Metabolism. 21:895-904.

17. Pimstone, B. L., D. Le Roith, S. Ebstein, and S. Kronheim. 1975. Disappearance rates of plasma growth hormone after intravenous somatostatin in renal and liver disease. J. Clin. Endocrinol. \& Metab. 41:392-395.

18. Baumann, G., M. Stolar, K. Amburn, C. P. Barsano, and B. C. DeVries. 1986. A specific growth hormone-binding protein in human plasma: initial characterization. J. Clin. Endocrinol. \& Metab. 62:134.

19. Herington, A. C., S. Ymer, and J. Stevenson. 1986. Identification and characterization of specific binding proteins for growth hormone in normal human sera. J. Clin. Invest. 77:1817.

20. Baumann, G., K. D. Amburn, and T. A. Buchanan. 1987. The effect of circulating growth hormone-binding protein on metabolic clearance, distribution, and degredation of human growth hormone. J. Clin. Endocrinol. \& Metab. 64:657-660.

21. Hattori, N., A. Shimatsu, Y. Kato, and H. Imura. 1990. Growth hormone and growth hormone binding protein in human urine. Kidney Int. 37:951-954.

22. Haffner, D., S. Zacharewicz, O. Mehls, U. Heinrich, and E. Ritz. 1989. The acute effect of growth hormone on GFR is obliterated in chronic renal failure. Clin. Nephrol. 32:266-269.

23. Girard, J., T. Erb, A. Pampalone A., A. N. Eberle, and J. B. Baumann. 1987. Growth hormone in urine: development of an ultrasensitive assay applicable to plasma and urine. Horm. Res. (Basel.) 28:71-80.

24. Tar, A., J. F. Hocquette, J. C. Souberbielle, J. P. Clot, R. Brauner, and M. C. Postel-Vinay. 1990. Evaluation of the growth hormone-binding proteins in human plasma using HPLC-gel filtration. J. Clin. Endocrinol. \& Metab. 71:1202-1207.

25. Blum, W. F., M. B. Ranke, and J. R. Bierich. 1986. Isolation and partial characterization of six somatomedin-like peptides from human plasma Cohn fraction IV. Acta. Endocrinol. 111:271-284.

26. Blum, W. F., M. B. Ranke, and J. R. Bierich. 1988. A specific radioimmunoassay for insulin-like growth factor II: the interference of IGF binding proteins can be blocked by excess IGF-I. Acta. Endocrinol. 118:374-380.

27. Blum, W. F., M. B. Ranke, K. Kietzmann, E. Gauggel, H. J. Zeisel, and J. R. Bierich. 1990. A specific radioimmunoassay for the growth hormone (GH)dependent somatomedin-binding protein: its use for diagnosis of GH deficiency. J. Clin. Endocrinol. \& Metab. 70:1292-1298.

28. Tait, J. F. 1963. Review: the use of isotopic steroids for the measurement of production rates in vivo. J. Clin. Endocrinol. \& Metab. 23:1285-1297.

29. Zilversmit, D. B. 1960. Design and analysis of isotopic experiments. Am. J. Med. 29:832-848.

30. SAS Institute. 1985. SAS User's Guide: Statistics, 5th ed. SAS Institute, Cary, NC.

31. Lee, P. D. K., R. L. Hintz, J. B. Sperry, R. C. Baxter, and D. R. Powell. 1989. IGF binding proteins in growth-retarded children with chronic renal failure. Pediatr. Res. 26:308-315.

32. Blum, W. F., M. B. Ranke, K. Kietzmann, B. Tönshoff, and O. Mehls. 1991. Growth hormone resistance and inhibition of somatomedin activity by excess of insulin-like growth factor binding protein in uremia. Pediatr. Nephrol. 5:539-544.

33. Johnson, V., and T. Maack. 1977. Renal extraction, filtration, absorption, and catabolism of growth hormone. Am. J. Physiol. 233:F185-F196.

34. Rabkin, R., T. I. Gottheiner, and V. S. Fang. 1981. Removal and excretion of immunoreactive rat growth hormone by the isolated kidney. Am. J. Physiol. 240:F282-F287.

35. Veldhuis, J. D., M. L. Johnson, L. M. Faunt, M. Mercado, and G. Baumann. 1993. Influence of the high-affinity growth hormone (GH)-binding protein on plasma profiles of free and bound $\mathrm{GH}$ and on the apparent half-life of $\mathrm{GH}$. J. Clin. Invest. 91:629-641. 
36. Bullier-Picard, F., M. C. Postel-Vinay, and C. Kayser. 1988. In-vivo uptake of human growth hormone in male rat liver. J. Endocrinol. 121:19-25.

37. Hussman, B., J. A. Gustafsson, and G. Anderson. 1988. Receptor-mediated endocytosis and degradation of bovine growth hormone in rat liver. $\mathrm{Mol}$. Cell. Endocrinol. 59:13-25.

38. Finidori, J., M. C. Postel-Vinay, and C. Kleinknecht. 1980. Lactogenic and somatotropic binding sites in liver membranes of rats with renal insufficiency. Endocrinology. 106:1960-1965.

39. Hruska, K. A., A. Korkor, K. Martin, and E. Slatopolsky. 1981. Peripheral metabolism of intact parathyroid hormone. J. Clin. Invest. 67:885-892.

40. Sorecki, K. L., and B. M. Brenner. 1981. Body fluid homeostasis. A contemporary overview. Am. J. Med. 70:77-86.

41. Baumann, G., K. Amrun, and M. A. Shaw. 1988. The circulating growth hormone ( $\mathrm{GH}$ )-binding protein complex: A major constituent of plasma $\mathrm{GH}$ in man. Endocrinology. 122:976-984.

42. Faria, A. C. S., J. D. Veldhuis, M. O. Thorner, and M. L. Vance. 1989. Half-time of endogenous growth hormone $(\mathrm{GH})$ disappearance in normal man after stimulation of $\mathrm{GH}$ secretion by $\mathrm{GH}$-releasing hormone and suppression with somatostatin. J. Clin. Endocrinol. \& Metab. 68:535-541.

43. Tönshoff, B., J. D. Veldhuis, U. Heinrich, and O. Mehls. 1991. Deconvolution analysis of spontaneous and stimulated growth hormone (GH) secretion in prepubertal children with chronic renal failure (CRF). Horm. Res. 35:28. (Abstr.)

44. Schaefer, F., J. D. Veldhuis, J. Jones, K. Schärer, and Cooperative Study Group on Pubertal Development in Chronic Renal Failure. 1993. Diminished growth hormone $(\mathrm{GH})$ production rate in peripubertal boys with chronic renal failure (CRF) and after renal transplantation (TX). Pediatr. Nephrol. 7 (Suppl.):C14. (Abstr.)

45. Baumann, G., and E. C. Abramson. 1983. Urinary growth hormone in man: Evidence for multiple molecular forms. J. Clin. Endocrinol. \& Metab. 56:305-311.

46. Hattori, N., Y. Kato, Y. Murakami, S. Hashida, E. Ishikawa, Z. Mohri, and $\mathrm{H}$. Imura. 1988. Urinary growth hormone levels measured by ultrasensitive enzyme immunoassay in patients with renal insufficiency. J. Clin. Endocrinol. \& Metab. 66:727-732.
47. Hocken-Koelega, A. C. S., W. H. L. Hackeng, T. Stijnen, J. M. Wit, S. M. P. F. Munick, and S. L. S. Drop. 1990. Twenty-four-hour plasma growth hormone (GH) profiles, urinary GH excretion, and plasma insulin like growth factor-I and-II levels in prepubertal children with chronic renal insufficiency and severe growth retardation. J. Clin. Endocrinol. \& Metab. 71:688-695.

48. Sherman, R. L., D. E. Drayer, B. R. L. Jones, and M. M. Reidenberg. 1983. $\mathrm{N}$-Acetyl- $\beta$-glucosaminidase and $\beta_{2}$-microglobulin, their urinary excretion in patients with renal parenchymal disease. Arch. Intern. Med. 143:1183-1192.

49. Harrison, J. F., G. S. Lunt, P. Scott, and J. D. Blainey. 1968. Urinary lysozyme, ribonuclease, and low-molecular-weight protein in renal disease. Lancet. i:371-382.

50. Weissberger, A. J., K. Y. Ho, and M. C. Stuart. 1989. Quantification of urinary growth hormone $(\mathrm{GH})$ excretion by centrifugal ultrafiltration and radioimmunoassay: appraisal of the relationship between $24 \mathrm{~h}$ urinary $\mathrm{GH}$ and mean $24 \mathrm{~h}$ serum GH levels in normal and abnormal states of GH secretion. Clin. Endocrinol. 30:687-698.

51. Girard, J. A., and N. Eberle. 1992. Clinical utility of urinary growth hormone. J. Endocr. 121:101-106.

52. Martha, P. M., K. M. Gorman, R. M. Blizzard, A. D. Rogol, and J. D. Veldhuis. 1992. Endogenous growth hormone secretion and clearance rates in normal boys, as determined by deconvolution analysis: relationship to age, pubertal status, and body mass. J. Clin. Endocrinol. \& Metab. 74:336-344.

53. Ritz, E., B. Tönshoff, S. Worgall, G. Kovacs, and O. Mehls. 1991. Influence of growth hormone and insulin-like growth factor-I on kidney function and kidney growth. Pediatr. Nephrol. 5:509-512.

54. Tönshoff, B., U. Heinrich, and O. Mehls. 1991. How safe is the treatment of uraemic children with recombinant human growth hormone? Pediatr. Nephrol. 5:454-460.

55. Tönshoff, B., M. Dietz, D. Haffner, C. Tönshoff, B. Stöver, and O. Mehls 1991. Effects of two years of growth hormone treatment in short children with renal disease. Acta. Paediatr. Scand. Suppl. 379:33-41.

56. Wühl, E., D. Haffner, B. Tönshoff, and O. Mehls. 1993. Predictors of growth response to rhGH in children before and after renal transplantation. Kidney Int. 44 (Suppl. 43):76-82. 